EXTENDED REPORT

\title{
Prediction of a major clinical response (BASDAI 50) to tumour necrosis factor $\alpha$ blockers in ankylosing spondylitis
}

\author{
M Rudwaleit, J Listing, J Brandt, J Braun, J Sieper
}

See end of article for authors' affiliations .....................

Correspondence to: DrM Rudwaleit, Medizinische Klinik I, Charité-Universitätsmedizin Berlin, Campus Benjamin Franklin, Hindenburgdamm 30, 12200 Berlin, Germany; martin.rudwaleit@charite. de

Accepted

21 December 2003

Published online first

21 March 2004

Background: TNF $\alpha$ blockers have been shown to be highly efficacious in patients with active ankylosing spondylitis (AS).

Objective: To identify parameters predicting the clinical response to TNF blockers in AS.

Methods: Patients with active AS participated in two placebo controlled, randomised trials conducted in Germany with infliximab $(n=69)$ and etanercept $(n=30)$, respectively. For inclusion in either trial patients had to have high disease activity (BASDAI $\geqslant 4$ ) and a spinal pain score (numerical rating scale $0-10$ ) $\geqslant 4$ despite treatment with NSAIDs. A major clinical response was defined as a $50 \%$ improvement of the initial BASDAI (BASDAI 50) after 12 weeks' treatment with active drug. Logistic regression likelihood ratio tests (univariate and multivariate), Student's $t$ test, and $\chi^{2}$ tests were performed.

Results: Univariate analysis showed the following to be predictors of a major response (BASDAI 50) to treatment: shorter disease duration $(p=0.003)$; lower BASFI $(p=0.007)$; younger age $(p=0.009)$; raised $\operatorname{ESR}(p=0.033)$; raised CRP ( $p=0.035)$. After adjustment for disease duration, BASFI, ESR, and CRP, but not age, remained significantly associated. After adjustment for disease duration and for BASFI, ESR, CRP, and in addition, a higher BASDAI were significantly associated with response. The best multivariate model built by stepwise regression contained the covariables disease duration, BASFI, BASDAI, and CRP.

Conclusion: A shorter disease duration, younger age, and a lower BASFI are predictors of a major clinical response to TNF blockers in active AS. Raised CRP and a higher BASDAl may also be valuable predictors. These data need to be confirmed in further studies.

A nkylosing spondylitis (AS) is a chronic inflammatory rheumatic disease affecting about twice as many men as women, with an estimated prevalence of $0.2-0.8 \% .^{1-3}$ The first symptoms normally occur in the second and third decade of life. ${ }^{4}$ Until recently, non-steroidal anti-inflammatory drugs (NSAIDs) and physical therapy were the only accepted treatment. In contrast with rheumatoid arthritis, there is no evidence that disease modifying antirheumatic drugs (DMARDs) such as methotrexate, sulfasalazine, leflunomide or others are effective for the axial manifestations, whereas there is some evidence, at least for sulfasalazine, that DMARDs might work in peripheral arthritis. ${ }^{5}$ Over the past 2 years several placebo controlled and open trials have shown a dramatic response in active AS to both tumour necrosis factor $\alpha(\mathrm{TNF} \alpha)$ blocking agents tested: infliximab and etanercept. ${ }^{6-13}$ In these trials $50-70 \%$ of patients showed an improvement of $50 \%$ or more in the Bath Ankylosing Spondylitis Disease Activity Index (BASDAI), a response rate which is at least as good, if not better, than the results for TNF $\alpha$ blocking treatments of other chronic inflammatory diseases.

Infliximab was approved by the regulatory authorities inside the European Community (EC) for the treatment of active AS in May 2003, while etanercept was approved in America in August 2003. Clinical trials with other TNF blockers such as adalimumab are in preparation. Given the high costs and the rare but potential risks ${ }^{14}$ of treatment with TNF blockers, patients considered as suitable candidates for this kind of treatment should be carefully selected by the treating rheumatologist. Hence, we were interested to identify clinical or laboratory parameters predicting a major clinical response to TNF blockers in active AS. To accomplish this task we analysed data from patients who were enrolled in two recently conducted randomised controlled trials with infliximab ${ }^{8}$ and etanercept, ${ }^{9}$ respectively.

\section{PATIENTS AND METHODS}

Data were retrieved from two placebo controlled, randomised trials with infliximab $(n=69)$ and etanercept $(n=30)$, respectively, conducted in Germany. Details of these trials have been reported elsewhere. ${ }^{8} 9$ For inclusion in either trial patients had to have AS according to the modified New York criteria and had to have active axial disease, defined as a BASDAI score of $\geqslant 4$ (scale 0-10, 0 meaning no activity and 10 high disease activity $)^{15}$ and a spinal pain score of $\geqslant 4$ (numerical rating scale $0-10$ ) despite concurrent treatment with NSAIDs. Thus, the primary focus of these trials was on treating axial symptoms (back pain). Raised acute phase reactants were not a requirement for inclusion in either trial. ${ }^{89}$ A major clinical response was defined as a 50\% improvement or more of the initial BASDAI (BASDAI 50) after 12 weeks of treatment with active drug (infliximab or etanercept). Table 1 shows that the patients' demographic and clinical characteristics and the response to treatment were comparable between the two trials. For this analysis, data from both trials were combined $(n=99)$.

\footnotetext{
Abbreviations: AS, ankylosing spondylitis; ASAS, Ankylosing Spondylitis Assessment Group; BASDAl, Bath Ankylosing Spondylitis Disease Activity Index; BASFI, Bath Ankylosing Spondylitis Functional Index; BASMI, Bath Ankylosing Spondylitis Metrology Index; BASRI, Bath Ankylosing Spondylitis Radiology Index; CRP, C reactive protein; DMARD, disease modifying antirheumatic drug; ESR, erythrocyte sedimentation rate; LRT, likelihood ratio test; MRI, magnetic resonance imaging; NSAID, non-steroidal anti-inflammatory drug; TNF $\alpha$, tumour necrosis factor $\alpha$
} 
Table 1 Patients' characteristics from the infliximab trial and the etanercept trial, and the combined trial group

\begin{tabular}{llll}
\hline Characteristics & $\begin{array}{l}\text { Infliximab trial } \\
(\mathbf{n}=69)\end{array}$ & $\begin{array}{l}\text { Etanercept trial } \\
(\mathbf{n}=30)\end{array}$ & $\begin{array}{l}\text { Total trial group } \\
(\mathbf{n}=99)\end{array}$ \\
\hline Male sex, No (\%) & $45(65)$ & $22(73)$ & $67(68)$ \\
Age (years), mean (SD) & $39.6(8.6)$ & $35.6(9.1)$ & $38,4(8.9)$ \\
Disease duration (years), mean (SD) & $15.6(8.8)$ & $13.03(8.6)$ & $14.8(8.8)$ \\
HLA-B27 positive, No (\%) & $61(88)$ & $27(90)$ & $88(89)$ \\
BASDAl & $6.4(1.3)$ & $6.6(1.1)$ & $6.4(1.2)$ \\
BASFI & $5.3(2)$ & $5.7(2.1)$ & $5.4(2)$ \\
CRP (mg/l), mean (SD) & $27.3(25.7)$ & $21.5(18.5)$ & $25.5(23.8)$ \\
Peripheral arthritis, mean (SD) & $41(59.4)$ & $19(63.3)$ & $60(60.6)$ \\
Enthesitis, mean (SD) & $37(53.6)$ & $19(63.3)$ & $56(56.6)$ \\
Ankylosis of sacroiliac joints (grade 4), mean (SD) & $23(33.3)$ & $11(36.7)$ & $34(34.39$ \\
BASRI lumbar spine (3-4)*, mean (SD) & $14(20.6)$ & $9(31.0)$ & $23(23.7)$ \\
BASRI cervical spine (3-4)*, mean (SD) & $17(27.0)$ & $3(11.1)$ & $20(22.2)$ \\
BASDAI 50 response, No (\%) & $36(52)$ & $19(63)$ & $55(56)$ \\
ASAS 40 response, No (\%) & $39(57)$ & $19(63)$ & $58(59)$ \\
\hline *Indicates advanced radiological changes of the spine (syndesmophytes of three vertebrae or more).
\end{tabular}

Logistic regression analysis (univariate and multivariate) with likelihood ratio tests (LRTs), Student's $t$ test, $\chi^{2}$ test, and Fisher's exact test using SPSS software was performed to investigate which of the following parameters assessed before treatment were associated with a BASDAI 50 response: age, sex, disease duration, BASDAI, morning stiffness (questions 5 and 6 of the BASDAI), Bath Ankylosing Spondylitis Functional Index (BASFI; scale 0-10, 0 meaning no restriction of function and 10 maximum restriction of function), ${ }^{16}$ Bath Ankylosing Spondylitis Metrology Index (BASMI) for the measurement of spinal mobility, ${ }^{17}$ Bath Ankylosing Spondylitis Radiology Index (BASRI) for sacroiliac joints and spine, ${ }^{18} \mathrm{C}$ reactive protein (CRP), erythrocyte sedimentation rate (ESR), HLA-B27, presence of peripheral arthritis, presence of enthesitis, patient global assessment, and physician global assessment. Because univariate results might be biased if there is no control for the influence of other important predictors, the following stepwise multivariate logistic regression analysis was performed. To control for a possible bias by disease duration all parameters were analysed again with a simultaneous adjustment for disease duration (bivariate regression). In a similar manner an adjustment was made for disease duration and for function. In the last step the results were examined by usual stepwise logistic regression analysis. The last observation carried forward method was applied to include five patients with missing values because of adverse events.

We also analysed the prediction of response if the Ankylosing Spondylitis Assessment Group (ASAS) 40 instead of the BASDAI 50 was applied to define a major clinical response. The ASAS 40 is a derivative from the ASAS 20, a criterion to assess response in NSAID trials. ${ }^{19}$ ASAS 20 is defined as an improvement of at least $20 \%$ in at least three of the four following domains: ( $a$ ) morning stiffness; $(b)$ pain; (c) function (BASFI); (d) patient global assessment; and no worsening in the potentially remaining domain. ${ }^{19}$ ASAS 40 differs from ASAS 20 in that an improvement of at least $40 \%$ instead of $20 \%$ is required.

\section{RESULTS}

Table 1 shows the characteristics of the patients from both trials. Overall, a BASDAI 50 response after 12 weeks was achieved by $55 / 99(56 \%)$ patients. Table 2 shows the demographic and clinical data of responders and nonresponders. Univariate analysis (each variable independently analysed) showed that the following were predictors of a major response (BASDAI 50) to treatment: (a) shorter disease duration (LRT result 9.1; $\mathrm{p}=0.003$ ); $(b)$ lower BASFI (LRT result 7.2; $\mathrm{p}=0.007$ ); (c) younger age (LRT result 6.9; $\mathrm{p}=0.009$ ); (d) raised ESR (LRT result 4.5; $\mathrm{p}=0.033$ ); and (e) raised CRP (LRT result 4.5; p=0.035) (table 3). BASMI, HLA-B27, peripheral arthritis, enthesitis, sex, morning stiffness, patient global assessment, physician global assessment, and BASRI did not predict response to treatment (table 3, some data not shown). Adjustment for disease duration (bivariate analysis) showed that BASFI, ESR, CRP, and in addition, HLA-B27 were significantly associated. Adjustment for disease duration and for BASFI (multivariate analysis) showed that ESR, CRP, and in addition, a higher BASDAI were significantly associated with response. The best multivariate model built by stepwise regression contained the covariables (prediction parameters) disease duration, BASFI, BASDAI, and CRP (table 3).

\section{Disease duration}

A significant decrease in the likelihood of achieving a major clinical response was found for each year of disease duration $(\mathrm{OR}=0.93$; univariate analysis) (table 3$)$. To illustrate the effect patients were grouped according to disease duration into three blocks ( $\leqslant 10$ years, $11-20$ years, $>20$ years). Again, a significant association with BASDAI 50 was found: among patients with a short disease duration of $\leqslant 10$ years $27 / 37$ (73\%) achieved BASDAI 50, compared with 19/33 (58\%) patients with a disease duration of 11-20 years, and 9/29 (31\%) patients with a disease duration of $>20$ years $\left(\chi^{2}=11.7 ; \mathrm{p}=0.003\right)$ (fig 1$)$.

\section{Functional status (BASFI)}

The significantly decreasing chance of achieving a BASDAI 50 response with increased levels of the BASFI (an increase in BASFI reflects a worsening functional status) is again demonstrated by grouping patients according to BASFI. Patients with lower BASFI scores at baseline showed a higher rate of BASDAI 50 response: 21/30 (70\%) patients with a BASFI $<4.5$ showed a major clinical response compared with $22 / 36(61 \%)$ patients with a BASFI between 4.5 and 6.5 , and with only $12 / 33(36 \%)$ patients with a high BASFI of 6.5 or more $\left(\chi^{2}=8.2 ; \mathrm{p}=0.017\right)$ (fig 2 ).

\section{Disease activity (BASDAI)}

The association of the BASDAI at baseline with a BASDAI 50 response after 12 weeks was weaker than those of function (BASFI) or of disease duration. When logistic regression analysis was used, disease activity (BASDAI) before treatment was only significantly associated with a major clinical response after adjustment for disease duration and function 
Table 2 Demographic and clinical parameters of responders and non-responders; response is defined as a $50 \%$ improvement of the initial BASDAI (BASDAI 50)

\begin{tabular}{llll}
\hline & $\begin{array}{l}\text { BASDAI 50 } \\
\text { responder } \\
(\mathbf{n}=55)\end{array}$ & $\begin{array}{l}\text { BASDAI 50 } \\
\text { non-responder } \\
(\mathbf{n}=44)\end{array}$ & p Value \\
\hline Male sex, No (\%) & $38(69)$ & $29(66)$ & 0.7 \\
Age (years), mean (SD) & $36.3(8.6)$ & $41.1(8.7)$ & 0.008 \\
Disease duration (years), mean (SD) & $12.5(8.2)$ & $17.8(8.7)$ & 0.002 \\
HLA-B27 positive, No (\%) & $51(93)$ & $37(84)$ & 0.9 \\
BASDAl, mean (SD) & $6.6(1.2)$ & $6.2(1.3)$ & 0.085 \\
BASFI, mean (SD) & $4.9(2.0)$ & $6.0(1.9)$ & 0.007 \\
CRP (mg/l), mean (SD) & $30.0(25.3)$ & $19.9(20.8)$ & 0.035 \\
\hline
\end{tabular}

(BASFI). This indicates that within various stages of function and disease duration the BASDAI before treatment does have predictive properties. We found a significant association of the BASDAI for the total population $(n=99)$ when patients were grouped into blocks of various ranges of BASDAI scores: whereas only $5 / 17(29 \%)$ patients with moderate disease activity (BASDAI 4-5) achieved a major clinical response (BASDAI 50), 50/82 (61\%) patients with high disease activity (BASDAI >5) achieved such a response $(\mathrm{OR}=3.8,95 \%$ confidence interval (CI) 1.2 to 11.7; Fisher's exact test $\mathrm{p}=0.024)$ (fig 3).

\section{Acute phase reactants}

Figure 4 shows that there was a clear correlation between a raised CRP at baseline and a higher chance of achieving a major treatment response (LRT result 4.5; $\mathrm{p}=0.035$ ). In addition, fig 4 illustrates the relation of CRP levels with the probability of a major treatment response depending on disease duration. As can be seen, the probability of patients with a short disease duration ( 5 years) but normal CRP levels achieving BASDAI 50 is $65 \%$ compared with only $30 \%$ in patients with a long disease duration ( 25 years) and normal CRP. Very high levels of CRP increase the chance of achieving BASDAI 50 in patients with short disease duration to $90 \%$ and in patients with long disease duration from $30 \%$ to $70 \%$.

\section{HLA-B27}

There was a trend for HLA-B27 positive patients with AS to achieve a BASDAI 50 response compared with HLA-B27 negative patients: 51/88 (58\%) HLA-B27 positive patients achieved BASDAI 50 whereas only 3/10 (30\%) HLA-B27 negative patients with AS did so $(\mathrm{p}=0.09)$. This difference, however, was not significant, which is probably related to the small number $(n=10)$ of HLA-B27 negative patients. Of note, in a bivariate model (after adjustment for disease duration) the association of HLA-B27 positivity with a major clinical response became just significant (LRT result 4.1; $\mathrm{p}=0.043$ ), which was lost again after controlling for both disease duration and for function (BASFI) in the multivariate analysis.

\section{Time course of response to treatment}

In patients who achieved BASDAI 50 the response to treatment was seen very rapidly during treatment. After 6 weeks of treatment with an active drug a BASDAI 50 response was seen already in $45 / 55$ (82\%) patients who achieved BASDAI 50 at week 12. Moreover, almost all responders at week 12 showed some improvement after 23 weeks (assessments were made at week 2 in the infliximab trial and week 3 in the etanercept trial): a BASDAI 20 response (20\% improvement of the initial BASDAI) after 23 weeks was found in 53/55 (96\%) patients who later achieved BASDAI 50 at week 12. In other words, only two of the BASDAI 50 responders at week 12 did not show at least $20 \%$ improvement of the BASDAI (BASDAI 20) already after 2-3 weeks. On the other hand, a BASDAI 20 response after 2-3 weeks did not reliably predict a BASDAI 50 response after 12 weeks because 25/78 (32\%) such patients (BASDAI 20 after 2-3 weeks) did not achieve BASDAI 50 at week 12 .

\section{ASAS 40 response criteria}

Instead of the BASDAI 50 as an indicator of a major treatment response we also performed a prediction analysis for ASAS 40, a composite index assessing the domains inflammation, function, pain, and patient global assessment. Of the 99 patients, 58 (59\%) achieved ASAS 40 after 12 weeks, which is similar to BASDAI 50 (table 1). When univariate analysis was applied, the same variables which

Table 3 Prediction of response: odds ratios (OR) and $95 \%$ confidence intervals (CI) of BASDAI 50 response; results are shown for univariate (total population and for each drug separately) and multivariate (total population only) logistic regression analysis

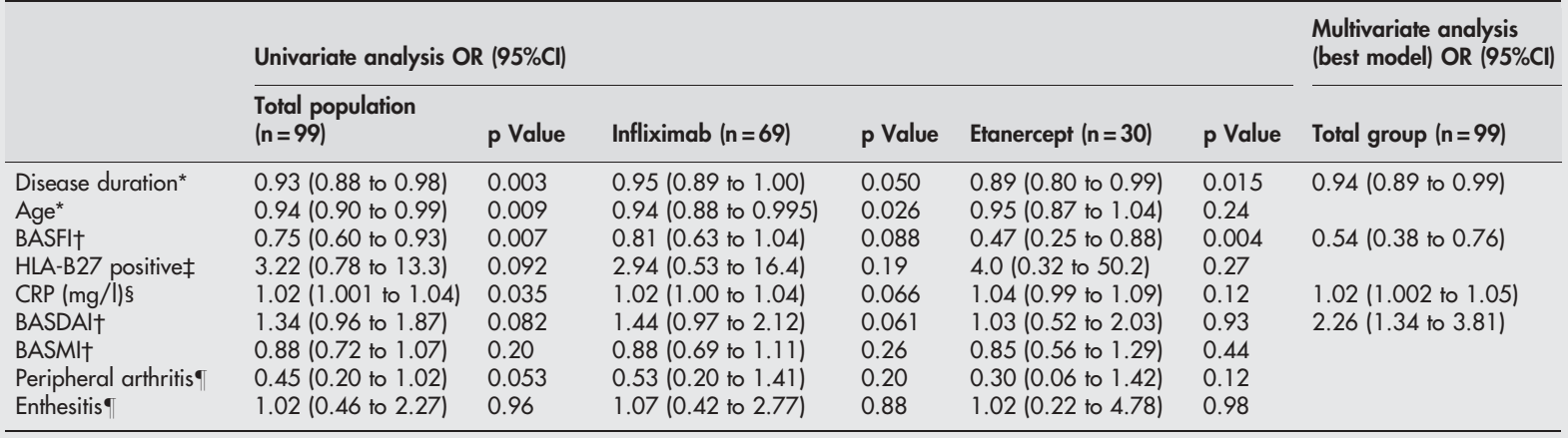

*OR refers to the risk of achieving a BASDAI 50 response per year of disease duration/age; †OR refers to the risk per one grade on a $0-10$ scale; $¥ O R$ refers to the risk if HLA-B27 is positive ( $v$ negative); §OR refers to the risk per $1 \mathrm{mg} / \mathrm{l}$ increase of CRP; $\uparrow$ OR refers to the risk if peripheral arthritis or enthesitis, respectively, is present ( $v$ absent). 


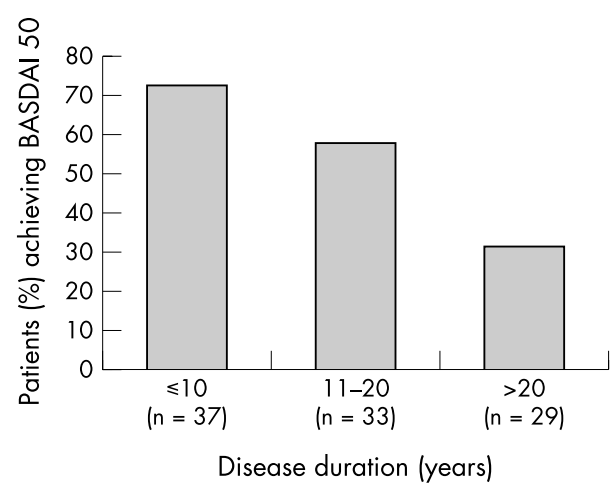

Figure 1 Relationship between disease duration and proportion of patients (\%) who achieved a BASDAI 50 response after 12 weeks. Here, patients $(n=99)$ were grouped into three blocks of disease duration $(\leqslant 10$ years, $11-20$ years, $>20$ years). Patients with shorter disease duration had a significantly higher chance of achieving BASDAI 50 than patients with longer disease duration $\left(\chi^{2}=11.7 ; p=0.003\right)$.

predicted response to treatment according to BASDAI 50 also predicted response according to ASAS 40: disease duration $(p=0.009)$, BASFI $(p=0.035)$, and CRP $(p=0.004)$.

\section{Specific drug effect}

An analysis of the variables predicting a major treatment response was also performed for each drug separately. As can be seen in table 3, there was no essential difference between the two drugs.

\section{DISCUSSION}

As far as we know, this is the first systematic analysis of parameters predicting a major clinical response to TNF blockers in active AS. To our knowledge similar attempts to analyse variables predicting a major treatment response have not been reported for other chronic inflammatory diseases which are also treated with TNF blockers. For this study, we took advantage of two recently conducted randomised controlled clinical trials with infliximab $(n=69)$ and etanercept $(n=30)$, comprising a total of 99 patients with AS. $^{89}$ The likelihood of achieving a major clinical response to TNF blockers in active AS was significantly higher in younger patients with shorter disease duration, better functional status, raised acute phase reactants, and higher disease activity. Moreover, there was a trend for HLA-B27 positivity to be related to a higher likelihood to respond. However, the small number of HLA-B27 negative patients in this dataset precluded definite conclusions about a potential role for HLAB27 as predictor of response.

Age and disease duration are closely related measures as the multivariate logistic regression analysis showed when adjustments for disease duration was done. In contrast, the functional status (BASFI) remained significantly associated with a major clinical response, suggesting a less strong correlation of BASFI with disease duration. The fact that younger patients with shorter disease duration and better functional status benefit from TNF blockers to a greater extent probably indicates that less structural (irreversible) damage has occurred and more acute inflammation is present in these patients. Interestingly, BASMI (reflecting mobility of the spine) and BASRI (reflecting radiological changes) did not predict response to treatment. Obviously, these indices are less discriminatory and may describe disease components which are different from those which comprise the BASFI. Of interest also is the rapid response to treatment. Almost all patients (96\%) who achieved a BASDAI 50 response at 12 weeks showed at least some improvement (BASDAI 20) after 2-3 weeks. Thus, patients who do not

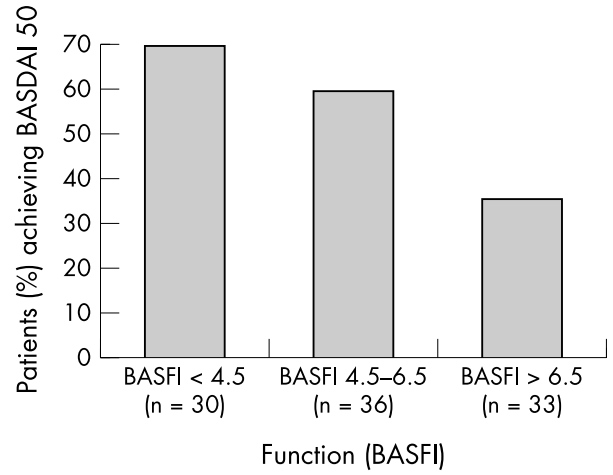

Figure 2 Relationship between functional status (BASFI) and proportion of patients (\%) who achieved a BASDAI 50 response after 12 weeks. Patients $(n=99)$ were grouped into blocks of various BASFI scores. Patients with lower BASFI scores (that is, better functional status) had a significantly higher chance of achieving BASDAI 50 than patients with higher BASFI scores (that is, worse functional status) $\left(\chi^{2}=8.2\right.$; $\mathrm{p}=0.017)$.

improve after this short interval by at least $20 \%$ are highly unlikely to achieve a major clinical response later on.

We found a clear correlation between raised acute phase reactants and response to treatment. Raised acute phase reactants were not a requirement for inclusion of patients either in the infliximab trial ${ }^{8}$ or in the etanercept trial. ${ }^{9}$ Of note, in the open French trial treating patients with AS with infliximab, ${ }^{13}$ only patients with a raised CRP $(>15 \mathrm{mg} / \mathrm{l})$ were included. In this study $92 \%$ of patients reported a $50 \%$ improvement of pain, and $84 \%$ showed a $50 \%$ improvement of the ASAS response criteria. ${ }^{19}$ Thus, the preselection of patients with raised CRP probably contributed to the extraordinarily high response rate in the French trial.

Interestingly, the disease activity index (BASDAI) did predict a major clinical response, but less strongly than disease duration and functional status. Overall, patients with high disease activity (BASDAI $>5$ ) responded more often than patients with moderate disease activity (BASDAI 4-5), but disease duration, age, and functional status were better predictors. In addition to using the BASDAI, disease activity could be also assessed by the presence of extraspinal manifestations such as peripheral arthritis, enthesitis, or uveitis. However, the percentage of patients with any of these symptoms was too small to allow for conclusive statistical analysis in the two treatment trials. Acute bony inflammation of

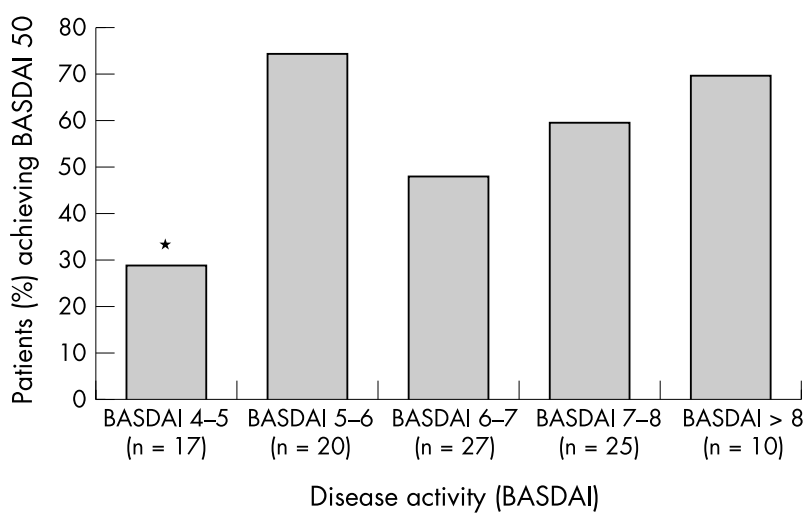

Figure 3 Relationship between disease activity (BASDAl) and proportion of patients (\%) who achieved a BASDAI 50 response after 12 weeks. Patients $(n=99)$ were grouped into blocks of various BASDAl scores. Patients with a BASDAI $>5$ had a significantly higher chance of achieving BASDAI 50 than patients with a BASDAI of $4-5(O R=3.8$, $95 \% \mathrm{Cl} 1.2$ to $11.7 ; p=0.024)$. 


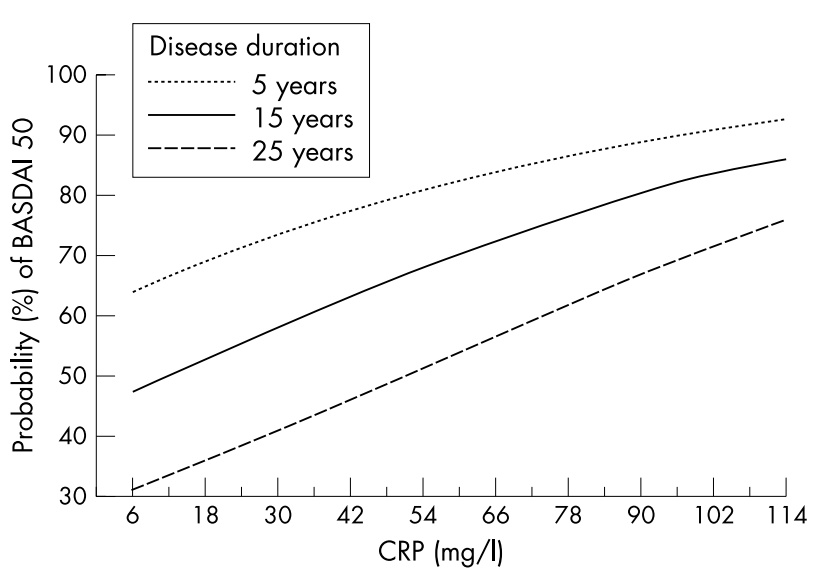

Figure 4 Probability of a BASDAl 50 response after 12 weeks depending on CRP levels at baseline and disease duration. The three curves were calculated by bivariate logistic regression analysis. They represent the expected probabilities of response for three selected levels of disease duration (5 years, 15 years, 25 years) and various levels of CRP.

the pelvis or the spine as detected by magnetic resonance imaging (MRI) may also be an indicator of disease activity, but there are presently only preliminary data available..$^{21}$

In patients with AS with longstanding disease more structural damage can be assumed. The back pain in patients with AS with longstanding disease is not always attributable to acute inflammation of the spine, small vertebral joints, or sacroiliac joints as is often the case in early disease but may be rather related to permanent mechanical changes. The differentiation between inflammatory and mechanical conditions as the cause of pain in patients with AS with advanced disease is often a challenge for the rheumatologist. Again, MRI of the spine and sacroiliac joints may aid in this distinction, but data on sensitivity and specificity of MRI in AS are still limited. ${ }^{22-24}$ Assuming that TNF blockers act mainly at sites where acute inflammation takes place it is not surprising that overall only a minority $(30 \%)$ of patients with disease duration of 20 years or longer showed a major clinical response to this type of treatment. However, the probability of responding can increase to $60-70 \%$ even in patients with longstanding disease if acute phase reactants as one measure indicating active disease are strongly raised (fig 4).

In general, the analysis of pooled data from two trials using two different anti-TNF agents, infliximab and etanercept, should be done with caution because there may be differences in the mode of action and efficacy between the two drugs. For example, etanercept is not effective in Crohn' disease, whereas infliximab is. However, the data from our trials (table 2 ) and all available data from trials performed by others to date do not indicate any difference in the clinical efficacy of the two drugs in active AS. When prediction parameters were analysed for infliximab and etanercept separately there was no relevant difference between the two drugs in our study (table 3 ). Furthermore, the two trials analysed herein were designed and conducted in the same centre, applying the same inclusion criteria, outcome parameters, and the same assessment tools, and are therefore much more comparable than pooled data from different centres with different study designs. Moreover, in rheumatoid arthritis the physician first decides whether a patient needs anti-TNF treatment and then decides on the compound he wants to use. Thus, to us analysis of the pooled data seems justified.

We chose the BASDAI 50 (at least 50\% improvement of the initial BASDAI) as the measure to define a good clinical response because (a) BASDAI 50 was one of the outcome measures in each of the two trials ${ }^{89}$ and $(b)$ the recently published "International ASAS consensus statement for the use of anti-TNF agents in AS" also recommends the use of BASDAI 50 as one of the primary measures to decide whether to continue anti-TNF treatment in AS in daily practice. ${ }^{25}$ We also applied the ASAS 40 instead of BASDI 50 to define a major clinical response and found no relevant difference in the parameters predicting such response.

It can definitely not be concluded from our data that TNF $\alpha$ blockers should not be offered to older patients with longstanding disease or higher BASFI because only a minority $(30-40 \%)$ of these patients did achieve a major treatment response. The decision to start anti-TNF treatment in AS should be made on the basis of the ASAS international consensus statement ${ }^{25}$ and for the individual patient, taking into account far more aspects related to personality, patient's preferences, quality of life, and also issues such as availability of the drug, rather than merely on the basis of those parameters analysed herein. Nevertheless, high costs and possible (especially in the long term), although rare, side effects may argue for a preselection of suitable patients in daily clinical practice. An expected rate of $70 \%$ or more of patients achieving an improvement of at least $50 \%$ of their disease activity would certainly shift the benefit-risk ratio largely towards benefit. More data on this issue will become available from continuing treatment trials with the inclusion of several hundreds of patients.

\section{ACKNOWLEDGEMENTS}

We are grateful to Professor G Valet, Max-Planck-Institute, Martinsried, Germany, for helpful discussions.

This study was supported by the BMBF (Kompetenznetz Rheuma), FKZ 01 GI9946.

\section{Authors' affiliations}

M Rudwaleit, J Brandt, J Sieper, Rheumatology, Department of Medicine, Charité-Universitätsmedizin Berlin, Campus Benjamin Franklin, Berlin, Germany

J Listing, Epidemiology, Deutsches RheumaForschungszentrum, Berlin, Germany

J Braun, Rheumazentrum Ruhrgebiet, Herne, Germany

\section{REFERENCES}

1 Sieper J, Braun J, Rudwaleit M, Boonen A, Zink A. Ankylosing spondylitis: an overview. Ann Rheum Dis 2002;61(suppl III):iiiz-18.

2 Saraux A, Guedes C, Allain J, Devauchelle V, Valls I, Lamour A, et al. Prevalence of rheumatoid arthritis and spondyloarthropathy in Brittany France. Societe de Rhumatologie de l'Ouest. J Rheumatol 1999;26:2622-7.

3 Braun J, Bollow M, Remlinger G, Eggens U, Rudwaleit M, Distler A, et al. Prevalence of spondylarthropathies in HLA-B27 positive and negative blood donors. Arthritis Rheum 1998;41:58-67.

4 Feldtkeller E, Khan MA, Van Der Heijde D, Van Der Linden S, Braun J. Age at disease onset and diagnosis delay in HLA-B27 negative vs. positive patients with ankylosing spondylitis. Rheumatol Int 2003:23:61-6.

5 Dougados M, Dijkmans B, Khan M, Maksymowych W, van der Linden S, Brandt J. Conventional treatments for ankylosing spondylitis. Ann Rheum Dis 2002;61 (suppl III):iii40-50

6 Brandt J, Haibel H, Cornely D, Golder W, Gonzalez J, Reddig J, et al. Successful treatment of active ankylosing spondylitis with the anti-tumor necrosis factor alpha monoclonal antibody infliximab. Arthritis Rheum 2000;43:1346-52.

7 Brandt J, Haibel H, Sieper J, Reddig J, Braun J. Infliximab treatment of severe ankylosing spondylitis: one-year followup. Arthritis Rheum 2001;44:2936-7.

8 Braun J, Brandt J, Listing J, Zink A, Alten R, Golder W, et al. Treatment of active ankylosing spondylitis with infliximab: a randomised controlled multicentre trial. Lancet 2002;359:1187-93.

9 Brandt J, Khariouzov A, Listing J, Haibel H, Sorensen H, Grassnickel L, et al. Six-month results of a double-blind, placebo-controlled trial of etanercept treatment in patients with active ankylosing spondylitis. Arthritis Rheum 2003; $48: 1667-75$.

10 Gorman JD, Sack KE, Davis JC Jr. Treatment of ankylosing spondylitis by inhibition of tumor necrosis factor alpha. N Engl J Med 2002;346:1349-56.

11 Marzo-Ortega H, McGonagle D, O'Connor P, Emery P. Efficacy of etanercept in the treatment of the entheseal pathology in resistant spondylarthropathy: a clinical and magnetic resonance imaging study. Arthritis Rheum 2001;44:2112-17. 
12 Maksymowych WP, Jhangri GS, Lambert RG, Mallon C, Buenviaje $H$, Pedrycz E, et al. Infliximab in ankylosing spondylitis: a prospective observational inception cohort analysis of efficacy and safety. J Rheumatol 2002;29:959-65.

13 Breban M, Vignon E, Claudepierre P, Devauchelle V, Wendling D, Lespessailles $E$, et al. Efficacy of infliximab in refractory ankylosing spondylitis: results of a six-month open-label study. Rheumatology (Oxford) 2002;41:1280-5.

14 Bresnihan B, Cunnane G. Infection complications associated with the use of biologic agents. Rheum Dis Clin North Am 2003;29:185-202.

15 Garrett S, Jenkinson T, Kennedy LG, Whitelock H, Gaisford P, Calin A. A new approach to defining disease status in ankylosing spondylitis: the Bath Ankylosing Spondylitis Disease Activity Index. J Rheumatol 1994;21:2286-91.

16 Calin A, Garrett S, Whitelock H, Kennedy LG, O'Hea J, Mallorie P, et al. A new approach to defining functional ability in ankylosing spondylitis: the development of the Bath Ankylosing Spondylitis Functional Index. J Rheumatol 1994;21:2281-5

17 Jenkinson TR, Mallorie PA, Whitelock HC, Kennedy LG, Garrett SL, Calin A. Defining spinal mobility in ankylosing spondylitis (AS). The Bath AS Metrology Index. J Rheumatol 1994;21:1694-8.

18 MacKay K, Mack C, Brophy S, Calin A. The Bath Ankylosing Spondylitis Radiology Index (BASRI): a new, validated approach to disease assessment. Arthritis Rheum 1998:41:2263-70.
19 Anderson JJ, Baron G, van der Heiide D, Felson DT, Dougados M. Ankylosing spondylitis assessment group preliminary definition of short-term improvement in ankylosing spondylitis. Arthritis Rheum 2001;44:1876-86.

20 Rudwaleit M, Brandt J, Listing J, Braun J, Sieper J. Is there a role for MRI in predicting the clinical response to TNF alpha blockers in ankylosing spondylitis? [abstract]. Ann Rheum Dis 2003;62(suppl I):97.

21 Braun J, Baraliakos X, Golder W, Brandt J, Rudwaleit M, Listing J, et al. Magnetic resonance imaging examinations of the spine in patients with ankylosing spondylitis, before and after successful therapy with infliximab: evaluation of a new scoring system. Arthritis Rheum 2003:48:1126-36.

22 Braun J, Bollow M, Eggens U, Konig H, Distler A, Sieper J. Use of dynamic magnetic resonance imaging with fast imaging in the detection of early and advanced sacroiliitis in spondylarthropathy patients. Arthritis Rheum 1994:37: 1039-45.

23 Marc V, Dromer C, Le Guennec P, Manelfe C, Fournie B. Magnetic resonance imaging and axial involvement in spondylarthropathies. Delineation of the spinal entheses. Rev Rhum Engl Ed 1997;64:465-73.

24 Bollow M, Enzweiler C, Taupitz M, Golder W, Hamm B, Sieper J, et al. Use of contrast enhanced magnetic resonance imaging to detect spinal inflammation in patients with spondyloarthritides. Clin Exp Rheumatol 2002;20(suppl 28):S167-74.

25 Braun J, Pham T, Sieper J, Davis J, van der Linden S, Dougados M, et al International ASAS consensus statement for the use of anti-TNF agents in patients with ankylosing spondylitis. Ann Rheum Dis 2003;62:817-24. 